\title{
Atendimento Psicológico Domiciliar: relato de uma experiência
}

Atención Psicológica Domiciliaria: relato de una experiência

Home Psychological Care: Report of an Experience

Marta Maria de Lima Alexandre

Pontifícia Universidade Católica de Minas Gerais - Minas Gerais - Brasil

Roberta Carvalho Romagnoli

Pontifícia Universidade Católica de Minas Gerais - Minas Gerais - Brasil

\section{RESUMO}

Este texto discute a prática do psicólogo em sua vertente clínica, focada na atenção à saúde no domicílio e em outros settings terapêuticos. Apresenta a experiência da prática do Atendimento Psicológico Domiciliar, não vinculado a uma instituição, em três bairros da região Oeste de Belo Horizonte, destacando o percurso histórico e conceitual da Atenção Domiciliar à Saúde (ADS), a primazia do SUS como precursor desse tipo de atenção, as dimensões e multiplicidades dessa prática. O processo de inserção da psicologia na Estratégia de Saúde da Família (ESF) convoca outras atuações clínicas para além da tradicional. Nesse contexto, a necessidade de conhecer o território é prioridade, extrapolando o setting do consultório privado e ampliando o acesso da população. Concluímos que o Atendimento Psicológico Domiciliar é um novo tipo de fazer clínico, que requer abertura dos profissionais, ainda com muitos desafios.

Palavras-chave: Atenção domiciliar. Território. Atendimento psicológico. Saúde mental.

\section{RESUMEN}

Este texto discute la práctica del psicólogo en su vertiente clínica, enfocada en la atención a la salud en el domicilio y en otros ajustes terapéuticos. Se presenta la experiencia de la práctica del Servicio Psicológico Domiciliar, no vinculado a una institución, en tres barrios de la región oeste de Belo Horizonte, destacando el recorrido histórico y conceptual de la Atención Domiciliaria a la Salud (ADS), la primacía del SUS como precursor de ese tipo Atención, las dimensiones y multiplicidades de esta práctica. El proceso de inserción de la psicología en la Estrategia de Salud de la Familia (ESF) convoca otras actuaciones clínicas más allá de la tradicional. En este contexto, la necesidad de conocer el territorio es prioridad, extrapolando el setting del consultorio privado y ampliando el acceso de la población. Concluimos que la atención psicológica domiciliaria es un nuevo tipo de hacer clínico, que requiere apertura de los profesionales, aún con muchos desafíos. 
Palabras clave: Atención domiciliar. Territorio. Atención psicológica. Salud mental.

\begin{abstract}
This text discusses the psychologist's practice in clinical aspect, focused on health care at home and other therapeutic settings. It presents the experience of the practice of Psychological Home Care, not linked to an institution, in three neighborhoods of the western region of Belo Horizonte, highlighting the historical and conceptual path of Home Health Care (ADS), the primacy of public institution SUS as a precursor of this work in Brazil, the dimensions and multiplicities of this practice. The process of insertion of psychology in the so-called Family Health Strategy (FHS) calls for other clinical activities beyond the traditional one. In this context, the need to get to know the territory is a priority, going beyond the setting of the private practice and expanding the access of the population. We conclude that psychological home care is a new type of clinical practice, which requires openness on the part of the professionals, still with many challenges.
\end{abstract}

Keywords: Home Care. Territory. Psychological care. Mental Health.

\section{Introdução}

A Atenção Domiciliar à Saúde (ADS), também conhecida como home care ou home health care, tem referência nos cuidados ou assistência domiciliares relacionados à cura pela medicina. De acordo com Amaral, Cunha, Labronici, Oliveira e Gabbai (2001), tanto no Egito Antigo do século XIII a.C., como na Grécia Antiga se assistia o enfermo no domicílio. Ressaltam-se os escritos de Hipócrates ao considerar eficiente o atendimento no domicílio. Os autores lembram o fundador da homeopatia, Samuel Hahnemann, que acreditava na luta do médico contra a doença independentemente do lugar e ficava junto aos enfermos em seus leitos domiciliares o maior tempo possível. Destacam também as ações de enfermagem lideradas por Lilian Wald, que no ano de 1796 já apontava os aspectos sociais e econômicos relacionados ao tratamento da doença. Com o seu pioneirismo, ela contribuiu para mudanças na história da assistência domiciliar à saúde e nos movimentos públicos da área de saúde dos EUA.

Como afirmam Amaral et al. (2001), nos anos 1950 surge maior necessidade de atenção aos problemas crônicos de saúde. Diminuía o índice das doenças contagiosas e os modelos de ADS começavam a ser uma alternativa à dificuldade das seguradoras norte-americanas para financiar a assistência. No entanto, aos poucos, os fundos governamentais passaram a direcionar recursos para os departamentos de saúde e a financiar esse tipo de cuidado. A prioridade da ADS voltada aos pacientes com doenças persistentes se mantém em vários outros países da Europa, especialmente a França.

Segundo Tavolari, Fernandes e Medina (2000), no Brasila experiência pioneira de ADS surgiu com o objetivo de “(...) desospitalizar doentes crônicos estáveis para desocupar uma parte dos leitos do hospital, que estava superlotado naquela época" (p.16);além disso,surgiu também,para reduzir a ocupação de leitos com pouca complexidade de assistência no Hospital do Servidor Público Estadual de São Paulo, no ano de 1967.Nesse sentido, Oliveira e Kruse (2017) explicam que a desospitalização “(...) propõe a economia de recursos humanos e materiais da instituição hospitalar com o deslocamento para o domicílio" (p.4). As autoras acrescentam que em 1997 foi publicada a primeira portaria que apresentou os objetivos para o atendimento domiciliar e normatizou essa modalidade no SUS como forma de institucionalizar a internação no domicílio. Nesse contexto, o 
atendimento domiciliar revela-se como prática recente entre as profissões de saúde. Essa modalidade existe também no caso do psicólogo hospitalar, como afirma Langaro (2017) “(...) ainda pouco discutido é o atendimento psicológico no domicílio enquanto parte das práticas do psicólogo hospitalar" (p.2).

Amaral et al. (2001) problematizam que diferentemente dos EUA, preocupados com processos judiciais sobre os profissionais de saúde da ADS, o Brasil experimentou a criação de estratégias de qualidade para atender também pacientes de alto risco, facilitando os debates e publicações a respeito dessa prática. A seguir outros fatores se somaram à prática da ADS, como a crescente mudança nos índices demográficos, o aumento da população idosa e, com isso, uma maior necessidade de atenção domiciliar.

Lacerda, Giacomozzi, Oliniski e
Truppel (2006) revelam estudos de documentos oficiais do Ministério da Saúde e ANVISA (Agência Nacional de Vigilância Sanitária) dos anos de 2004 e 2006, nos quais a atenção domiciliar à saúde está conceituada em: atenção domiciliar, atendimento domiciliar, internação domiciliar e visita domiciliar. Todas essas modalidades da ADS são complementares e interdependentes como apontam os autores, articulando-se às práticas das políticas públicas de saúde, assistência social, saneamento, educação, de acordo com a realidade dos grupos e indivíduos. Entretanto, a atenção domiciliar é mais ampla, pois envolve promoção, prevenção e tratamento de doenças e reabilitação em domicílio. Em geral essa modalidade é realizada com a participação de equipe multidisciplinar, cliente e família e engloba as outras acima citadas.

$\mathrm{O}$ atendimento domiciliar se restringe às atividades relacionadas à assistência domiciliar, cuidado e atividades ambulatoriais e, para Lacerda et al. (2006) "circunstâncias agudas ou crônicas de saúde”. Em síntese “(...) o atendimento domiciliar compreende todas as ações, sejam elas educativas ou assistenciais, desenvolvidas pelos profissionais de saúde no domicílio do cliente, direcionadas a ele próprio e/ou a seus familiares" (Lacerda et al., 2006, p.92). Por sua amplitude, esse termo também é nomeado como assistência ou cuidado domiciliar. Para Tavolari, Fernandes e Medina (2000), “(...) o Atendimento Domiciliar envolve ações menos complexas, multiprofissionais ou não, que podem ser comparadas a um "consultório em casa" (p.17).

Por sua vez, a internação domiciliar trata-se de um cuidado mais intensivo apropriado ao domicílio e com supervisão de equipe específica, incluindo o possível uso de equipamentos e materiais. E o conceito de visita domiciliar é definido como "(...) o mais difundido no sistema de saúde brasileiro e nas práticas de saúde na comunidade." (Lacerda et al., 2006, p.93). Nessa forma de assistência, os profissionais buscam entender e avaliar a realidade dos clientes, problemas e necessidades, orientá-los, fornecendo subsídios educativos de cuidados com a saúde e possível envolvimento do indivíduo, da família e da comunidade.

Vale destacar que a visita domiciliar tem um lugar no planejamento das equipes de saúde da família na Atenção Básica. Segundo Cunha e Sá (2013):

As VDs permitem conhecer: as condições de vida e habitação das famílias, as relações que estabelecem no ambiente doméstico, as condições de adoecimento daquela família, e consequentemente, podem facilitar o planejamento e o direcionamento das ações visando a promoção da saúde e $\mathrm{o}$ fortalecimento do autocuidado. (p.6)

A prática de visita domiciliar também atende aos pressupostos da Reforma Psiquiátrica para indivíduos que passaram por internação psiquiátrica e estão em processo de reintegração social e familiar. Segundo Pietroluongo e Resende (2007) o objetivo principal da visita domiciliar é capacitar as 
famílias para “(...) lidar com os problemas suscitados com o convívio com a loucura, evitando as internações recorrentes e consequente alienação social e a cronificação do usuário de saúde mental" (Pietroluongo \& Resende, 2007, p.2). O papel do profissional na escuta diferenciada contribui para a desconstrução de preconceitos socialmente construídos em torno da loucura. As autoras avaliam que:

Enfocando a visita domiciliar, para que o profissional possa abarcar a dinâmica familiar subjetiva, é necessária a modificação do conceito e da culpa dos familiares com a consequente valorização de seus saberes e habilidades e da loucura enquanto doença orgânica e incapacitante, devolvendo o poder de verdade à palavra do louco (Pietroluongo \& Resende, 2007, p.2).

Vários autores pesquisados afirmam que ainda não há consenso sobre os conceitos da ADS (Lacerda et al., 2006; Amaral et al., 2001). Nesse sentido, tomaremos o termo Atendimento Psicológico Domiciliar - APD para o relato da experiência deste trabalho, pela proximidade com o objeto de discussão proposto. Esta experiência versa sobre a modalidade de atenção à saúde no domicílio e em outros settings terapêuticos distintos, que despontam como uma nova experiência de intervenção para os profissionais de saúde. Neste contexto, tem como objetivo pensar prioritariamente a prática do psicólogo do ponto de vista da atuação clínica, tomados os desafios e acertos desta, no texto que se segue.

\section{O SUS como pioneiro na Atenção Domiciliar}

Para pensar as peculiaridades da atuação do psicólogo em outros settings terapêuticos distintos do consultório particular, no campo da saúde pública e privada, é necessário situar em primeiro lugar, a inserção desse profissional nos serviços já existentes relacionados ao tema deste trabalho:
Atendimento Psicológico Domiciliar - APD e outros settings terapêuticos.

Para Alexandre (2015) o Sistema Único de Saúde (SUS) continua sendo o maior empregador do profissional de psicologia no país, seguido do Sistema Único de Assistência Social (SUAS), tomando o total de psicólogos registrados no Conselho Federal de Psicologia (257.380) no ano de 2015 (Conselho Federal de Psicologia, 2015). Pesquisa realizada pela autora em $2015^{1}$ mostra o crescimento em $167 \%$ no número de psicólogos inseridos no SUS (38.423). Revela, ainda, uma inserção de $30 \%$ no número de profissionais em atuação nos estabelecimentos que atendem ao SUS, na atenção básica. A presença do psicólogo soma-se ainda ao que se distribuiu da seguinte maneira: nas 4.401 equipes do NASF (Núcleo de Apoio à Saúde da Família), nas 149 Equipes de Consultório na Rua (ECR), nas 852 Equipes Multiprofissionais de Atenção Domiciliar (EMAD) e Multiprofissionais de Apoio e nas 307 Equipes de Atenção à Saúde do Sistema Penitenciário (EPEN) vinculadas à Atenção Básica (AB).

Esse crescimento traz novos desafios referentes à melhoria da formação e dos requisitos para prática no campo da saúde, principalmente no nível da atenção básica, no qual encontramos o Serviço de Atenção Domiciliar, Equipes de Consultório na Rua, Equipes de Atenção à Saúde do Sistema Penitenciário, entre outros. Contudo, a prática do Atendimento Psicológico Domiciliar ainda é pouco pesquisada e conhecida, embora também siga crescendo no campo da saúde pública e privada, com aspectos relevantes que partem da relação custo-benefício à humanização do tratamento. O Conselho Federal de Psicologia (CFP, s/d) aponta que essa prática de atendimento psicológico é voltada para pessoas que apresentam dificuldades ou impedimentos de locomoção, patologias ou razões que as impossibilitam de

\footnotetext{
${ }^{1}$ Pesquisa realizada pela autora em agosto de 2015, com dados do Cadastro Nacional dos Estabelecimentos de Saúde do Brasil (CNES) (Brasil, 2015).
} 
procurar hospital ou consultório para o tratamento. Estas situações sugerem a convivência familiar para recuperação ou melhoria da qualidade de vida dentro dos limites da própria condição, além de que a família residente no domicílio deve concordar coma realização do atendimento, facilitando um local apropriado para a qualidade do trabalho e a sua privacidade.

Desse modo, equipes multiprofissionais direcionam a prática da ADS para desospitalização de pacientes com doenças persistentes liberados de leitos hospitalares, como visto na experiência do Núcleo de Assistência Domiciliar Interdisciplinar (NADI) do Hospital das Clínicas da Faculdade de Medicina da USP. No entanto, como pretendemos relatar, trata-se de uma prática atual que, pelos motivos acima expostos, também desperta o interesse das pessoas que desejam um atendimento psicológico mais próximo à sua vida diária em casa ou mesmo nos locais de trabalho.

$\mathrm{O}$ atendimento domiciliar no Brasil, instituído pela Portaria ${ }^{\circ} 2.029$ (2011), conta com 514 Equipes Multiprofissionais de Atenção Domiciliar (junho/2015) e 338 Equipes Multiprofissionais de Apoio, nas quais atuam psicólogos, entre os demais profissionais de saúde. Destacamos que a atenção domiciliar:

É desenvolvida por meio do exercício de práticas de cuidado e gestão, democráticas e participativas, sob forma de trabalho em equipe, dirigidas a populações de territórios definidos, pelas quais assume a responsabilidade sanitária, considerando a dinamicidade existente no território em que vivem essas populações. (Brasil, 2012).

O Documento intitulado "Diretrizes para a Atenção Domiciliar na Atenção Básica", produzido pelo Departamento de Atenção Básica, contém as diretrizes com o objetivo de orientar a organização dos serviços de atenção domiciliar na atenção básica no
Brasil. Espera-se que os profissionais sejam capazes de atuar com criatividade e senso crítico, mediante uma prática humanizada, competente e resolutiva, que envolva ações de promoção, prevenção, recuperação e reabilitação (Brasil, 2012).

Essa prática também se articula com a proposta de clínica ampliada, conceituada pela Política Nacional de Humanização como um dispositivo teórico e prático que tem como objetivo favorecer a dimensão clínica do adoecimento e do sofrimento, sempre atenta tanto à singularidade do sujeito quanto à complexidade do processo saúde/doença. Permite o enfrentamento da fragmentação do conhecimento e das ações de saúde e seus respectivos danos e ineficácia (Brasil, 2013). A Política Nacional de Humanização se inclui nessa perspectiva e a atenção domiciliar também, como afirma Langaro (2017) esta "caracteriza-se por ações interdisciplinares em resposta a uma avaliação global e tem entre seus principais objetivos a integralidade, o reforço da autonomia, a humanização dos serviços de saúde, a comunicação efetiva e a qualidade de vida" (p.3).

Com base no princípio da territorialização, a $\mathrm{AB}$ deve ser responsável pela atenção à saúde de todas as pessoas adscritas. Desta forma, a Atenção Domiciliar é atividade inerente ao processo de trabalho das Equipes de Atenção Básica, sendo necessário que estejam preparadas para identificar e cuidar dos usuários que se beneficiarão desta modalidade de atenção, o que implica adequar certos aspectos na organização do seu processo de trabalho, bem como agregar certas tecnologias necessárias para realizar o cuidado em saúde no ambiente domiciliar. O território é a base principal desse tipo de atenção que:

Utiliza tecnologias de cuidado complexas e variadas que devem auxiliar no manejo das demandas e necessidades de saúde de maior frequência e relevância em seu território, observando critérios de risco, vulnerabilidade, resiliência e o 
imperativo ético de que toda demanda, necessidade de saúde ou sofrimento devem ser acolhidos. (Portaria n. 2.488, 2011).

$A$ atenção domiciliar junto às equipes da $A B$ se mostra uma atuação inventiva que inclui a troca de saber, a relação com diferentes abordagens sobre a saúde mental, a família, a realidade dos territórios, as concepções sobre saúde-doença.Essa prática convoca novas atuações para os psicólogos, atentas a essas questões, que se distanciam da prática tradicional.

De acordo com Alexandre (2015) notase que a psicologia se mantém articulada a uma inserção com ênfase na clínica. Embora se verifique o crescimento dos profissionais de psicologia nos estabelecimentos do SUS, prevalece no ano de 2015a atuação clínica dos psicólogos nos níveis secundário e terciário do sistema, como policlínicas, clínicas especializadas, consultórios, diagnose e terapia, hospitais geral e dia, hospitais especializados e CAPS/CERSAM, prontosocorro e unidades de emergência, somando 26.919 profissionais em atuação nesses estabelecimentos, em um total de $70 \%$ dos psicólogos cadastrados pelo SUS (38.423) (Alexandre,2015). Por sua vez, o número de psicólogos com vínculo na atenção básica corresponde a $30 \%$ do total cadastrado no SUS em junho de 2015 (11.504), atuantes nos centros de apoio à saúde da família, postos de saúde, centros de saúde, unidades básicas de saúde e unidades mistas de saúde, unidade de atenção à saúde indígena, unidade de atenção em regime residencial e serviço de atenção domiciliar isolado (Home Care).

Acrescenta-se ainda, que aqueles profissionais de psicologia que não atendem ao SUS (23.100) estão inseridos, principalmente, nos consultórios (15.066), clínicas especializadas/ambulatórios especializados (4.976), policlínicas (1.396), hospital geral/pronto-socorro (515), hospital especializado/hospital dia/pronto atendimento (366), unidade de serviço de apoio de diagnose e terapia (432), onde se inclui o serviço de assistência domiciliar privado (Alexandre, 2015). Nesse sentido, a inserção da psicologia nas instituições de saúde privada e de saúde pública ocorre principalmente no campo da clínica.

Nesse contexto, a ADS está em ascensão entre as práticas do SUS, principalmente por meio da $\mathrm{AB}$, mas também em experiências da saúde privada. No entanto, ainda não está desenvolvida e articulada à formação e capacitação dos profissionais da saúde. Pensar essa prática para o profissional de psicologia implica retomar o conceito de clínica psicológica imbricada à clínica médica e seus limites enquanto prática liberal, privada e individualizante. Pois a prática tradicional de saúde ainda se coloca como referência para muitos profissionais de psicologia. É preciso tomar como referência as questões éticas potenciais de um novo espaço facilitador para o rompimento de padrões tradicionais do atendimento psicológico no âmbito privado e se conectar às necessidades das relações sociais da comunidade, da família, considerando a garantia de cidadania nos territórios e, sobretudo, a produção coletiva.

O filósofo francês Michel Foucault destacou as práticas discursivas em sua história e a produção do objeto de estudo da medicina, centradas na doença ordenada como saber científico e fundamento da medicina na modernidade dos séculos XVIII e XIX. Nessa época instaurou-se o biopoder, ou seja, o poder sobre os corpos e o saber sobre a vida, sobre o sujeito e a espécie humana (Foucault, 1999). Esse tipo de poder atua sobre o sujeito e a população e está articulado a mecanismos de regulamentação da vida, da morte, da biologia, do meio ambiente, estabelecido como poder disciplinar e biopolítica. Moreira, Romagnolie Neves (2007) apontam que esses dois eixos mostram a ligação entre saber e poder, a partir da qual emergem os sistemas de vigilância da subjetividade. "Esses sistemas de controle social são praticados pela Medicina e também pela Psicologia" (Moreira et al.,2007,p.612). A partir disso, a medicina 
estabelece o estatuto do homem saudável e "normal", regula políticas e tecnologias, exercendo um controle disciplinar mais especializado e tecnológico.

Apesar da herança da medicina sob a psicologia, Moreira et al. (2007) ressaltam a diferenciação entre a clínica médica focada na observação, no diagnóstico e as tecnologias empregadas na cura orgânica e a clínica psicológica focada na escuta do sofrimento do sujeito. Assim, o paradigma da psicoterapia se vincula a um espaço reservado ao segredo da demanda do sujeito e não necessariamente a uma patologia, fortalecendo o caráter individual da clínica psicológica, marcada pelo pensamento da sociedade moderna com o modelo individualista. A psicologia, entre outras ciências humanas, surge então ligada aos interesses da nova classe detentora do poder: a burguesia, cuja tradição se associava a uma prática de controle e higienização. Portanto, o contexto da prática clínica era distante do contexto social e político e se dedicava a manter o individualismo atrelado à lógica tradicional do sistema.

Mais tarde, na década de 70, grupos de psicólogos se engajavam nos movimentos políticos contra a ditadura e carreavam posicionamentos críticos que culminaram com discussões no campo da clínica e da política nos anos 1980. Esses questionamentos a respeito da prática clínica liberal e privada mexem com a neutralidade idealizada numa concepção de sujeito universal, a-histórico e apolítico e aos poucos alargam os horizontes para produção de subjetividade no plano coletivo conectado ao espaço social e político.

A psicologia segue repensando a constituição de um novo tipo de fazer clínico para sua atuação não apenas na saúde pública, como também em outras dimensões territoriais da saúde e settings terapêuticos apropriados à prática da profissão; na qual emerge uma dimensão coletiva em outro plano da produção de subjetividade, diferenciado dos consultórios e clínicas particulares e/ou públicas, tais como: atendimento domiciliar e em locais de trabalho, de que trata esta discussão. Essa atuação requer abertura para outro tipo de exercício clínico, de um setting terapêutico vivo no espaço domiciliar, diferenciado do espaço tradicionalmente concebido pelo psicólogo. Merhy (2002) citado por Neves, 2008) se refere ao trabalho vivo, que opera pela capacidade de experimentar relações de encontros, sendo que estes ultrapassam os saberes tecnológicos estruturados, o que significa dizer que:

Ao afirmar que o trabalho em saúde é centrado no trabalho vivo em ato, mostra que este não pode ser globalmente capturado pela lógica do trabalho morto, expresso pelos equipamentos e pelo saber tecnológico estruturado, pois se afirma em tecnologias relacionais, nos encontros entre subjetividades que portam um grau de liberdade significativo nas escolhas do modo de fazer esta produção. $\mathrm{O}$ ato clínico em saúde se dá em meio à existência efetiva do trabalho vivo em ato, e deste modo implica uma imprevisibilidade que impossibilita, fora do encontro, marcar a subsunção de um pólo sobre outro, de uma valise sobre a outra, pois ele é construído pela ação territorial dos atores em cena, "no ato intercessor do agir em saúde." (Merhy, 2002 citado por Neves, 2008, p. 1954).

O trabalho vivo do ato clínico se dá nos territórios múltiplos das cidades e amplia as dimensões que podemos ter desse espaço que acolhe e desacolhe as subjetividades que se articulam com toda singularidade territorial, experimentando a diferenciação em contato com o processo de subjetivação ali constituído. É um processo que se revela heterogêneo, desestabiliza e reconduz o sujeito a novas experimentações na vida da cidade/comunidade e reserva um lugar social e histórico àquele que se constituiu nomear cidadão. Esse indivíduo de direitos é o mesmo indivíduo filosófico-jurídico do campo das forças produtivas e políticas como prescrição 
universal do poder disciplinar e da biopolítica que vimos acima. Ao mesmo tempo, esse biopoder se põe a inventar novas normas para certo número de indivíduos: louco, morador em situação de rua, usuário de drogas, entre outros, sujeitados à instância normalizadora. Formas de gerir a vida calcadas nas produções científicas e nas práticas discursivas das ciências, dentre elas a Psicologia, sobretudo em sua vertente clínica.

A partir desse viés podemos refletir que uma prática clínica requer entender minimamente essa lógica relacional do sujeito com o território que o constitui, com as forças de "fora" que o compõem. Tal prática convoca o profissional a se colocar numa postura reflexiva e de práxis frente às condições de negatividade do cidadão que está em sofrimento psíquico, inscritas em nossa cultura na figura da desrazão, alienação, privação, destituída de vários direitos sociais, produzindo a imagem da periculosidade da loucura, que se mantém na contemporaneidade. Assim, essa prática convoca também a criar outras formas de intervir que levem em consideração essas capturas e enquadramentos experimentados no território.

Nesse contexto, interessa-nos pensar como a prática do psicólogo nos territórios da ADS se lança em agenciamentos potentes tecidos entre os afetos produzidos junto aos indivíduos em sofrimento, famílias, profissionais envolvidos nas relações e como circulam os fluxos de invenção e mudanças de vida em sua dimensão ético-política. Lancetti (2004) afirma que:

A produção da loucura e o controle social operam no domicílio e a Reforma Psiquiátrica, se quiser recuperar seu espírito revolucionário, precisa livrar a batalha da cidadania no espaço familiar, no tempo e na velocidade das máquinas cibernéticas e dar prioridade ao mais grave e mais difícil. (Lancetti, 2004, p.68).
A ADS se encontra no território com a loucura e outros modos de existência, enquanto lugar de passagem, espaço para os sonhos e desejos que se apresentam nas relações com os desafios da vida experimentada de maneira singular pelos sujeitos. O território oferece outras dimensões para a relação clínica que se dá nos movimentos, nos encontros que podem surgir enquanto setting em espaços diversos (nas casas, nas ruas, nas praças, nas salas improvisadas das UBS, mas, sobretudo, apostando na capacidade de afetar e ser afetado). Lancetti (2006) entende que “(...) o setting é a montagem, o cenário ou a situação; espaço dentro-fora facilitador da comunicação (...)" (Lancetti, 2006, p.20) e fundamenta o que denomina clínica peripatética, uma situação móvel das conversações e pensamentos que acontecem quando se vai aos encontros, às vezes de surpresa, caminhando junto às famílias que apresentavam graves dificuldades, transitando pelas cidades com pacientes psicóticos. Essas práticas transpõem espaços institucionais como os portões de clínicas e hospícios, indo além dos consultórios. O autor aponta, também, os “(...) novos settings como férteis para a produção de subjetividade e cidadania" (Lancetti, 2006, p.21). Além disso, relata diversas experiências conduzidas por ele numa clínica praticada em movimento, respeitando a complexidade da produção em saúde mental.

Lancetti (2006) sinaliza a paixão pela diferença e a disposição para trabalhar "em ambiente não protegido" (p.103) e acentua que psicólogos, psiquiatras, terapeutas ocupacionais, assistentes sociais ou enfermeiros podem vestir avental, estar diplomados ou pós-graduados, mas, se não estiverem "imbuídos da atração pela loucura e pela impossibilidade e gosto de cuidar e produzir mudança", sua "ação será insignificante" (Lancetti, 2006, p.103). O autor traz uma concepção de clínica cartográfica, inspirado em pensamentos da esquizoanálise de Deleuze e Guattari, na perspectiva do mapa que não se fixa na origem, mas nos deslocamentos, no qual são 
apontados os processos de subjetivação e dessubjetivação para lidar com grupos familiares nas intervenções das equipes de saúde mental.

Pensando não somente a clínica, mas também o sujeito, Silva e Carvalhaes (2016) evidenciam a presença de duas tendências para se apreender a subjetividade, uma primeira, e ainda dominante na psicologia, que insiste nesta como resultado de processos de estruturação interna, que entende a dimensão subjetiva como predominantemente individual, a histórica e com relações secundárias com a dimensão sociocultural; e uma segunda, que localiza a subjetividade em constante experimentação com a realidade heterogênea com elementos ambientais, políticos, tecnológicos e socioculturais, entre outros. Os autores atestam ainda que a necessidade de se pensar a subjetividade nas relações, para além do modo indivíduo é convocada pela inserção dos psicólogos, sobretudo nas políticas públicas.

Para focar o campo da clínica, entendemos que essa segunda proposta também embasa a necessidade de criação de uma clínica ampliada, como vimos na saúde mental e na política de humanização. Essa mesma necessidade emerge na inserção do psicólogo no campo da assistência social, que lida com um conceito de clínica "que ultrapassa muito além do indivíduo, e compreende as questões coletivas e políticas", como salientam Dettmann, Aragão e Margotto (2016, p.362). Clínica atenta às relações com a prática, ciente do contexto no qual se insere e da multideterminação da realidade.

Mansano (2011) aponta deslocamentos da clínica no domínio do consultório, no qual se deve levar em consideração, bem mais do que o indivíduo, a importância dos encontros e de seus efeitos. Assim, "a clínica volta-se para a experimentação e invenção de modos de vida que aumentem a potência dos seus partícipes e, na medida do possível, também daqueles com os quais eles mantêm alguma vizinhança afetiva" (Mansano, 2011, p.65).
Seja como clínica ampliada, social e política, seja como trabalho ou como clínica peripatética, inserida ou não nas políticas públicas, com certeza essas modalidades desestabilizam o plano da clínica tradicional e convocam novas formas de manejo e de enquadre desse fazer clínico.

\section{Práticas do Atendimento Psicológico Domiciliar}

O Atendimento Psicológico Domiciliar (APD) quando assume a condução assistencial atende pacientes em tratamento prolongado, os acidentados, oncológicos, idosos, portadores de doenças persistentes e familiares que necessitam de ajuda e solicitam a presença do psicólogo para lidar com sintomas diversos. Laham (2004) se refere ao medo desses pacientes, que se vêem inseguros pela ausência da tecnologia hospitalar no domicílio ou apresentam sintomas depressivos pelo diagnóstico repentino de doenças e consequentes mudanças de vida, de papéis sociais e familiares, sentimento de culpa para com os familiares pela relação de dependência e tarefas geradas. A autora registra que nesse tipo de assistência domiciliar é o paciente ou os seus familiares que dizem como o profissional "deve se comportar em sua residência: onde sentar, se tem permissão para entrar no banheiro, no quarto, enfim, na intimidade da família” (Laham, 2004, p.4).

Diferente em alguns aspectos desse tipo de assistência psicológica domiciliar na ADS,trazemos para discussão a prática do atendimento psicológico às pessoas que procuram o profissional para uma psicoterapia em domicílio ou no escritório de advocacia, no ateliê de costura, em outros locais de trabalho, onde se constitui outro tipo de relação e de setting terapêutico. Esse modo de atendimento necessita de um manejo dos elementos-chave que se articulam à prática profissional da psicoterapia de acordo com os princípios éticos da profisssão. Significa, em primeiro lugar, construir-se um setting terapêutico apropriado e que proporcione reserva para a realização do atendimento. 
Lembramos que o atendimento domiciliar por si possibilita um vínculo mais estreito, pela proximidade entre o profissional, o cliente e sua família. Segundo Laham (2004), esse tipo de atendimento:

... permite maior contato com a realidade concreta do paciente, havendo a possibilidade de se observar características da dinâmica familiar que não aparecem nos atendimentos nas instituições de saúde, que podem e devem ser utilizadas como dados para $\mathrm{o}$ psicodiagnóstico. (Laham, 2004, p.5)

No entanto, implica distinguir a todo tempo os limites da intimidade para não se colocar em risco o objetivo do trabalho, já que os manejos para realizá-lo vão se revelando no dinamismo do processo terapêutico. Borges e D'Oliveira (2011) revelam que o atendimento no domicílio não só fortalece o vínculo, mas pode favorecer a comunicação. Contudo, nem sempre é possível realizar o trabalho psicoterapêutico no espaço domiciliar, como por exemplo, o caso de uma cliente ameaçada de violência pelo esposo, que buscava o divórcio e não sabia da possibilidade de ter a sessão gravada por ele em sua residência. $O$ primeiro encontro já possibilitou a mudança imediata do setting para seu ateliê de costura, após o encerramento da sessão. A cliente se apresentava segura de sua opção pelo atendimento domiciliar/local de trabalho e argumentava sua impossibilidade para ser atendida em consultório, pois a partir da situação em que se encontrava na relação conjugal e com os filhos, se dizia impedida de se afastar do trabalho e da residência naquele momento.

Nota-se que o trabalho do psicólogo domiciliar é peculiar ao ambiente e à demanda trazida pelo cliente, exigindo flexibilidade e abertura para uma relação inventiva a partir do primeiro encontro, pois é uma prática que exige dinamismo diante dos movimentos que cada situação oferece. Além disso, leva em consideração o território e as forças que lá operam, nesse caso em direção à violência, à reprodução e até mesmo à autoprodução de outros modos de existência.

Entretanto, esse tipo de atendimento, algumas vezes apresenta limites: interferências e imprevistos durante os encontros (telefone, campainha, crianças que invadem o espaço, sons de vizinhos, cachorros, entre outros), mas também permite o envolvimento entre psicólogo e cliente para avaliar e criar alternativas em cada momento. "A possibilidade de ocorrência de imprevistos desse tipo deve ser explicada ao cliente no momento do contrato" (Laham, 2004, p.4).

Outra cliente iniciou a psicoterapia na residência, um apartamento aparentemente pequeno reservando a sala ao setting terapêutico, onde se encontravam um sofá, uma cadeira e a mesa com uma jarra d'água e dois copos. Algumas sessões foram realizadas em seu escritório de advocacia, próximo à residência, quando seu esposo se encontrava de férias e ficaria mais tempo em casa. Registra-se que os locais escolhidos pela cliente demonstram com clareza sua opção pelo atendimento psicológico próximo ou na própria residência, revelados por ela como prioridade de comodidade, tempo, segurança, elementos próprios das relações na contemporaneidade.

Uma mãe solicitou que visitasse sua filha de 25 anos em sua residência. Moravam juntas em um apartamento de dois quartos. Segundo a mãe da cliente, em 2008 a mesma "começou a ver bichos nas paredes do quarto, ouvir vozes, falar como se fosse com alguém, gritar, sorrir alto e gesticular de forma agressiva, abrindo gavetas do seu quarto". Na primeira visita a jovem disse que "pouco antes de ser internada, havia brigado com uma amiga que gostava tanto como uma irmã". Continuou dizendo que "por causa da doença, pensei que estava apaixonada por ela e cometi a besteira de dizer isso, tentar beijá-la e ela se afastou de mim". Afirmou ainda que a voz que escutava era a mesma da amiga, que dizia que "eu iria morrer" e "fui ficando nervosa com isso". Após este momento a mãe disse que o surto se desencadeou e a cliente foi internada 
em hospital psiquiátrico durante três meses. Após o terceiro encontro em sua residência, sofreu nova crise e internação, dessa vez por tentativa de matar a mãe e a si própria, com diagnóstico psiquiátrico de esquizofrenia paranoide. Devido à peculiaridade do caso, as sessões foram realizadas em consultório próximo a sua residência. Após um ano com encontros semanais, essa cliente trabalhou em farmácia, depois em confecção de artesanato e há dois anos não apresenta delírios, alucinações ou internações. Neste caso, a visita domiciliar foi suficiente para definição dos rumos do atendimento e garantia do acompanhamento clínico psicológico, não por se tratar de um caso de sofrimento psíquico, mas por sua singularidade.

Escutar a mãe (família) na visita domiciliar propiciou um processo de desconstrução da impotência e da culpa diante da loucura. Isto abriu espaço para melhorar a participação da jovem em atividades como produção de artesanato, passeios da comunidade, mais convivência com outros membros da família. Além disso, propiciou-se uma relação mais dialógica com a mãe para os cuidados e enfrentamentos das dificuldades na administração dos medicamentos, como na problematização com a psiquiatra para troca dos mesmos, devido aos efeitos colaterais que imobilizavam a vida da cliente.Lembra-se Pietroluongo e Resende (2007) quando ressaltam o objetivo principal da visita domiciliar no que se refere a capacitar a família para lidar com os problemas que surgem no convívio com a loucura e evitar as internações recorrentes, a cronificação e consequente alienação social do usuário de saúde mental. Nesse caso foi possível também questionar o uso abusivo dos medicamentos, inclusive de anticoncepcionais, que deixavam a cliente mais irritada e agitada na tensão prémenstrual, transitando por outras possibilidades que instigavam sua participação na vida social, de trabalho e familiar. Longe da normalização, o APD pode ajudar a concretizar a capacitação da família, que é um passo para a inclusão social do portador de sofrimento psíquico, que passa a viver como cidadão segundo os objetivos da Reforma Psiquiátrica Antimanicomial.

Ressaltamos que os domicílios dos casos acima citados estão na região Oeste de Belo Horizonte e os clientes atendidos se articulam com uma rede de equipamentos e serviços públicos e privados vinculados à saúde, educação, religião, centros comunitários. Há, assim, a necessidade de o profissional conhecer bem o território, para as possíveis intervenções no decorrer do processo terapêutico. Muitas vezes a demanda trazida pelo cliente envolve a experiência cotidiana com os serviços públicos e privados oferecidos e com outros profissionais que lá se encontram. É preciso questionar a construção de saberes que ainda carregam preconceitos e estigmas acerca da loucura, reservando a ela um lugar exclusivo de doença orgânica, que estimula a cultura da periculosidade da mesma. Tais perspectivas distanciam-se da constituição complexa de um cidadão biopsicossocial, sujeito que estabelece potentes relações discursivas, capaz de se deparar com seu próprio sofrimento psíquico e produzir uma subjetividade que é singular a cada ser que habita essa terra, sejam loucos ou aparentemente não loucos.

\section{Considerações Finais}

No Atendimento Psicológico Domiciliar, o profissional de psicologia vai se deparar, já no início de sua prática, com a cultura, o contexto social e territorial, os acontecimentos multidimensionais e os meios disponíveis a cada sujeito e sua família para constituir uma relação de encontros e um processo terapêutico. Esse processo poderá potencializar uma relação de vínculo e confiança para uma perspectiva de sentido e autonomia do sujeito envolvido, e da própria família em alguns casos. Nesse contexto, cresce a necessidade de compromisso e dedicação do profissional à complexidade de uma relação existencial territorial, respeitada a relação ética no espaço íntimo do domicílio ou local de trabalho, seja do sigilo, das condições 
de escuta ou do conforto para a garantia de um processo favorável à realização do trabalho.

Cabe destacar que os problemas encontrados no percurso desse tipo de atendimento não se restringem à demanda de quem busca terapia domiciliar, mas abarcam situações variadas do ambiente escolhido, inclusive de suas limitações, como também do contexto social, familiar e das possíveis articulações com ações oferecidas pelos equipamentos de saúde, comunitários, igrejas, entre outros, que exigem conhecimento e pesquisa do profissional da realidade local/regional. Essa conexão propicia saídas criativas na condução do processo terapêutico.

O Atendimento Psicológico Domiciliar surge ainda como uma prática em saúde mental no cotidiano das nossas cidades, capaz de problematizar, vislumbrar sobre possíveis alternativas para os impasses que se apresentam nas relações das cidades e das famílias com a loucura, encarando-os como desafios instigantes a todo tempo. A partir da discussão a respeito do lugar que o cidadão louco ocupa na sociedade, os modos de exclusão, as paredes "invisíveis" que se encontram nas cidades tentando impedir o acesso e experimentação dos territórios, concluímos acerca da necessidade da ocupação dos espaços de outras maneiras, não sendo o território apenas um lugar de passagem, onde não existe espaço para os sonhos e desejos. Estas formas são pensadas para incluir, aceitar as diferenças e singularidades que produzem subjetividade. É através das vivências, das relações e vínculos que podemos construir uma cidade mais digna, habitada por todos e experimentada de maneira a considerar a história de vida de cada sujeito, como território da existência.

\section{Referências}

Alexandre, M.M. L. (2015). O psicólogo nas trilhas dos processos de subjetivação na atenção básica à saúde/SUS: sentidos de uma prática cotidiana com as Equipes de Saúde da Família de Brumadinho. Dissertação de Mestrado, Programa de
Pós-graduação em Psicologia, Pontifícia Universidade Católica de Minas Gerais, Belo Horizonte, MG.

Amaral, N. N. do, Cunha, M. C. B., Labronici, R. H. D. D., Oliveira, A. S. B., \& Gabbai, A. A. (2001). Assistência Domiciliar à Saúde (Home Health Care): sua História e sua Relevância para o Sistema de Saúde Atual. Revista Neurociências, 9 (3), 111117. Recuperado em 10 de janeiro, 2017, de

http://www.revistaneurociencias.com.br/edi coes/2001/RN\%2009\%2003/Pages\%20fro m\%20RN\%2009\%2003-5.pdf.

Borges, R., \& D'Oliveira, A. F. P. L. (2011). A visita médica domiciliar como espaço para interação e comunicação em Florianópolis, SC. Interface Comunicação, Saúde, Educação, 37 (15). Recuperado em 21 de março, 2017, de http://www.scielo.br/pdf/icse/2011nahead/a op0611.

Brasil. (2013). Política Nacional de Humanização. Recuperado em 8 de fevereiro, $2017 \mathrm{de}$ http://camaralebonregis.sc.gov.br/wpcontent/uploads/2014/05/Academia-daSa\%C3\%BAdeslides.pdf.

Brasil. (2012). Caderno de Atenção

Domiciliar (Vol. 1). Brasília: Ministério da Saúde. Recuperado em 19 de agosto, 2015, de

http://189.28.128.100/dab/docs/publicacoes /geral/cad_vol1.pdf.

Brasil. (psicologia brasileira apresentada em números. [S. 1.]: CFP. Recuperado em 15 de agosto, 2015, de http://www2.cfp.org.br/infografico/quantos -somos/. 2015). Pesquisa (Tabela 2 e 3) DATASUS. Brasília: Ministério da Saúde. Recuperado em 10 de agosto, 2015, de http://tabnet.datasus.gov.br/cgi/deftohtm.ex e?cnes/cnv/proc02br.def.

Conselho Federal de Psicologia. (2015). A

Conselho Federal de Psicologia (s/d).

Dúvidas frequentes. Recuperado em 12 de fevereiro, 2017, de http://crp16.org.br/orientacoes/comomontar-um-consultorio/. 
Cunha, M. S. da, \& Sá, M. de C. (2013). A visita domiciliar na estratégia de saúde da família: os desafios de se mover no território. Interface - Comunicação, Saúde, Educação, 17(44), 61-73. Recuperado em 21 março, 2017, de http://www.scielo.br/pdf/icse/v17n44/a06v 17n44.pdf.

Dettmann, A. P. da S., Aragão, E. M. A.\& Margotto, L. R. (2016). Uma perspectiva da Clínica Ampliada: as práticas da Psicologia na Assistência Social. Fractal: Revista de Psicologia, 28(3), 362-369. Recuperado em 7 de junho, 2017 de https://dx.doi.org/10.1590/1984-0292/1232.

Foucault, M. (1999). Aula de 17 de março de 1976. In: Foucault, M. Em defesa da Sociedade (p.285-319). São Paulo: Martins Fontes.

Lacerda, M. R., Giacomozzi, C. M., Oliniski, S. R., \& Truppel, T. C. (2006). Atenção à Saúde no Domicílio: modalidades que fundamentam sua prática.Revista Saúde e sociedade, 2(15), 88-95. Recuperado em 12 janeiro, 2017, de http://www.scielo.br/pdf/sausoc/v15n2/09.p df.

Laham, C. F. (2004). Peculiaridades do atendimento psicológico em domicílio e o trabalho em equipe. Psicologia Hospitalar, 2(2). Recuperado em 15 janeiro, 2017, de http://pepsic.bvsalud.org/scielo.php?script $=$ sci_arttext\&pid=S167774092004000200010.

Lancetti, A. (2004). Notas sobre clínica e política. Revista Latino americana de Psicologia Fundamental, VII(3), 67-69. Recuperado em 12 junho, 2017, de http://www.scielo.br/pdf/rlpf/v7n3/14154714-rlpf-7-3-0067.pdf.

Lancetti, A. (2006). Clínica peripatética. São Paulo: Hucitec.

Langaro, F. (2017). "Salva o Velho!": Relato de Atendimento em Psicologia Hospitalar e Cuidados Paliativos. Psicologia: Ciência e Profissão, 37(1), 224-235. Recuperado em 15 janeiro, 2017, de https://dx.doi.org/10.1590/1982$\underline{3703000972014 .}$.
Mansano, S. R. V. (2011) Clínica e potência: algumas considerações sobre a experiência dos encontros em Gilles Deleuze. Mnemosine, 7(2), 64-74.

Moreira, J. de O., Romagnoli, R. C., \& Neves, E. de O. (2007). O surgimento da clínica psicológica: da prática curativa aos dispositivos de promoção da saúde. Psicologia: ciência e profissão, 27(4), 608-621. Recuperado em 10 de janeiro, 2017, de http://pepsic.bvsalud.org/pdf/pcp/v27n4/v2 7n4a04.pdf.

Neves, C. A. B. (2008). Cartografando na saúde os "inconscientes que protestam" [Resenha de "Saúde: a cartografia do trabalho vivo", de E. E. Merhy]. Cadernos de Saúde Pública, 24(8), 1953-1957. Recuperado em 20 de agosto, 2015, de http://www.scielo.br/pdf/csp/v24n8/23.pdf.

Oliveira, S. G., \& Kruse, M. H. L. (2017). Melhor em casa: dispositivo de segurança. Texto \& Contexto Enfermagem, 26(1). Recuperado em 7 de junho, 2017 de https://dx.doi.org/10.1590/010407072017002660015.

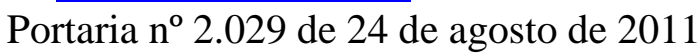
(2011). Institui a Atenção Domiciliar no âmbito do Sistema Único de Saúde (SUS). Brasília: Ministério da Saúde. Recuperado em 18 de maio, 2015, de http://bvsms.saude.gov.br/bvs/saudelegis/g m/2011/prt2029_24_08_2011.html.

Portaria n. 2.488 de 21 de outubro de 2011 (2011). Aprova a Política Nacional de Atenção Básica, estabelecendo a revisão de diretrizes e normas para a organização da Atenção Básica, para a Estratégia Saúde da Família (ESF) e o Programa de Agentes Comunitário de Saúde (PACS). 2011. Recuperado em 18 de maio, 2015, de http://bvsms.saude.gov.br/bvs/saudelegis/g m/2011/prt2488_21_10_2011.html.

Pietroluongo, A. P. da C., \& Resende, T. I. M. de. (2007). Visita domiciliar em saúde mental: o papel do psicólogo em questão. Psicologia: Ciência e Profissão, 27(1), 22-31. Recuperado em 16 de dezembro, 2016, de 
http://www.scielo.br/pdf/pcp/v27n1/v27n1a 03.pdf.

Silva, R. B., \& Carvalhaes, F. F. de. (2016). Psicologia e políticas públicas: impasses e reinvenções. Psicologia \& Sociedade, 28(2), 247-256. Recuperado de https://dx.doi.org/10.1590/180703102016v28n2p247.

Tavolari, C. E. L., Fernandes, F., \& Medina, P. (2000). O desenvolvimento do home health care no Brasil. Revista de Administração em Saúde, 3(9), 15-18.Recuperado em 10 de janeiro, 2017, de http://www.cqh.org.br/portal/pag/anexos/ba ixar.php?p_ndoc=246\&p_nanexo=\%2029.

Dados sobre as autoras:

- Marta Maria de Lima Alexandre é graduada em Serviço Social pela Universidade Federal de Pernambuco (jan/1987), graduada em Psicologia pela Pontifícia Universidade Católica de Minas Gerais (dez/2013) e Mestre em Psicologia pela Pontifícia Universidade Católica de Minas Gerais (out/ 2015). Foi fundadora da Confederação das Mulheres do Brasil, Federação das Mulheres Pernambucanas, Associação das Mulheres Winnie Mandela (SP) e presidente da Federação das Mulheres Mineiras até 2015.

- Roberta Carvalho Romagnoli possui graduação em Psicologia pela Universidade Federal de Minas Gerais (1986), mestrado em Psicologia (Psicologia Social) pela Universidade Federal de Minas Gerais (1996), doutorado em Psicologia (Psicologia Clínica) pela Pontifícia Universidade Católica de São Paulo (2003) e pós-doutorado em Análise Institucional pela Université Cergy-Pontoise, França (2011). Atualmente é Professora Adjunto III da Pontifícia Universidade Católica de Minas Gerais. Tem experiência na área de Psicologia Clínica, com ênfase em Intervenção Terapêutica, atuando principalmente nos seguintes temas: família, saúde e saúde mental, assistência social, clínica ampliada, análise institucional e esquizoanálise. Aborda a Psicologia como uma prática teórico-política que aponta para processos de subjetivação que ora são disciplinadores, reprodutores, ora são inventivos. É professora e coordenadora do Programa de Pós-Graduação da PUC-Minas e bolsista produtividade PQ 2 do CNPq e foi pesquisadora Mineiro da FAPEMIG (20142016). 